\title{
Fecundity, embryo size and embryo loss in the estuarine shrimp Salmoneus carvachoi Anker, 2007 (Crustacea: Alpheidae) from a tidal mudflat in northeastern Brazil
}

\author{
Mário Vitor Oliveira ${ }^{1,3}$, Ana Carla Costa-Souza ${ }^{2,4}$, Rodolfo Mariano ${ }^{1,5}$ \& Alexandre Oliveira Almeida ${ }^{2,6}$ \\ 1 Universidade Estadual de Santa Cruz (UESC), Departamento de Ciências Biológicas (DCB). Ilhéus, BA, Brasil. \\ ${ }^{2}$ Universidade Federal de Pernambuco (UFPE), Centro de Biociências (CB), Departamento de Zoologia. Recife, PE, Brasil. \\ ${ }^{3}$ ORCID: 0000-0002-8487-4631.E-mail: mario_biovitor@hotmail.com \\ ${ }^{4}$ ORCID: 0000-0002-8556-888X. E-mail: accostabio@yahoo.com.br \\ ${ }^{5}$ ORCID: 0000-0001-7304-2007. E-mail: rodolfomls@gmail.com \\ ${ }^{6}$ ORCID: 0000-0003-0470-8658. E-mail: aoalmeida.ufpe@gmail.com
}

\begin{abstract}
Studies on fecundity and embryo size have been frequently used to infer about the reproductive potential, embryogenesis, and the energy investment in embryo production in crustaceans. These parameters are relevant to the knowledge of life-history and diversity of reproductive strategies developed by this group. This study addressed the embryo production by the estuarine shrimp Salmoneus carvachoi Anker, 2007, a poorly known caridean shrimp. We investigated whether there was (1) a correlation between fecundity and carapace length, (2) an increase in embryo volume along the embryonic development, and (3) loss of embryos along development. In addition, we investigated whether the esternite length and height and width of the pleura of the second abdominal somite were good predictors of fecundity. A total of 53 embryo-carrying individuals were collected in December 2016 and February 2017 in a tidal mudflat from the estuary of the Paripe River, Ilha de Itamaracá, Pernambuco, Brazil. The carapace length ranged from 3.23 to $4.64 \mathrm{~mm}(3.78 \pm 0.26 \mathrm{~mm})$. Among those, 25 individuals had embryos in initial stage, 5 in intermediate stage and 15 in final stage. Fecundity ranged from 14 to 67 (33.65 \pm 12.51 embryos) and was weakly correlated with carapace length. However, fecundity was strongly correlated with the width of the second sternite and width of the pleura of the second abdominal somite. Embryo volume increased markedly (93\%) from the initial to the final stage of development. This increase might be due to water uptake to facilitate the membrane rupture at the onset of larvae hatching. There was significant loss of embryos only between the initial and intermediate stage. Future studies on the embryo production by other species of Salmoneus Holthuis, 1955 are necessary to understand and compare these aspects of reproductive biology.
\end{abstract}

Key-Words. Caridea; Abdominal space; Embryogenesis; Reproductive biology; Reproductive potential.

\section{INTRODUCTION}

Among the several reproductive aspects studied in crustaceans, fecundity and embryo size are important indicators of the reproductive potential, embryogenesis, and energy investment in embryo production. These aspects are relevant to the knowledge of life-history and type of reproductive strategy adopted by each species (Corey \& Reid, 1991; Anger \& Moreira, 1998; Hattori \& Pinheiro, 2003). Generally, the reproductive strategy can be affected by genetic and environmental factors (especially temperature and food availability) (Sastry, 1983; Lardies \& Wehrtmann, 1997; Bazán et al., 2009). In caridean shrimps, these strategies may vary intraspecificaly, between populations from different habitats, and interespecificaly, between species living in the same habi- tat (Corey \& Reid, 1991; Anger \& Moreira, 1998; Pavanelli et al., 2010).

Among the various approaches in the study of crustacean reproductive biology, linear and nonlinear regression models are frequently used to describe the relationships between fecundity, embryo volume and mass, ovary size, body size and mass, among others (Corey \& Reid, 1991; Anger \& Moreira, 1998). Positive correlations between fecundity and carapace length have been reported by most studies on shrimps of the infraorder Caridea, indicating that fecundity increases as females increase in size. This relationship demonstrates that the ability to produce oocytes is positively related to female growth. In addition, the larger the female the larger the abdominal space (where the embryos are carried) (Balasundaram \& Pandian, 1982; Bauer, 1991; Anger \& Moreira, 
1998). The increase in embryo volume and the concomitant embryo loss along the embryo development have also been observed in carideans (Balasundaram \& Pandian, 1982; Corey \& Reid, 1991; Anger \& Moreira, 1998). Within the family Alpheidae, this has been seen in species of the genus Alpheus Fabricius, 1798 (FernándezMuñoz \& García-Raso, 1987; Bauer, 1991; Corey \& Reid, 1991; Wehrtmann \& Graeve, 1998; Atkinson et al., 2003; Pavanelli et al., 2008, 2010; Harikrishnan et al., 2010; Costa-Souza et al., 2014; Pescinelli et al., 2016; Soledade et al., 2017), Betaeus Dana, 1852 (Lardies \& Wehrtmann, 1997, 2001) and Synalpheus Spence Bate, 1888 (Corey \& Reid, 1991; Hernáez et al., 2010; Rebolledo et al., 2014).

Salmoneus Holthuis, 1955 is the third richest genus among alpheids, with more than 50 species distributed worldwide (De Grave \& Fransen, 2011; Anker, 2011a, b; Komai \& Anker, 2012; Anker et al., 2014; Anker \& Lazarus, 2015; Komai et al., 2015; Ďuriš \& Horká, 2016). Salmoneus carvachoi Anker, 2007 is distributed in the Western Atlantic and can be found in Mexico, Guadeloupe, Venezuela, and Brazil (from Paraíba to São Paulo) (Anker, 2007; Vera-Caripe et al., 2015). This estuarine shrimp is commonly found in burrows in muddy sediments, mangroves, mud flats, and under rocks and debris (Christoffersen, 1982; Anker, 2007, 2010; Almeida et al., 2012). Studies about this species are scarce and limited to taxonomy and distribution [(e.g., Ramos-Porto et al., 1994, as S. ortmanni (Rankin, 1898); Anker, 2007, 2010; Almeida et al., 2012)], life-history and population structure, symbiotic relationships with other crustaceans, and possible mating and sexual systems (Oliveira et al., 2015). The occurrence of simultaneous hermaphroditism in S. carvachoi was suggested based on the observation of the appendix masculina in all individuals, including those carrying embryos, as well as the observation of pairs formed by two brooding individuals (Oliveira et al., 2015). Salmoneus carvachoi has been recorded in the burrows of the snapping shrimps Alpheus estuariensis Christoffersen, 1984 and A. chacei Carvacho, 1979, as well as in the burrows of the mud shrimp Axianassa australis Rodrigues \& Shimizu, 1992 (Ramos-Porto et al., 1994, as S. ortmanni; Almeida et al., 2012; Oliveira et al., 2015).

Up to the present, there is no information on any aspect of embryo production by Salmoneus. Therefore, the aim of this study was to investigate the embryo production in S. carvachoi and whether (1) there was a correlation between fecundity and carapace length; (2) if there was an increase in embryo volume along development; and (3) if there was loss of embryos along the development, as seen in many other caridean shrimps.

In caridean shrimps, the first three abdominal somites provide the abdominal space for embryo incubation (Bauer, 2004). The pleurae of the second abdominal somite in carideans overlaps the pleurae of first and third somites (Bauer, 2004). As this is the largest pleura, this structure may contribute to create more space for the brood and protect the embryos of S. carvachoi. In addition, the size of the second abdominal sternite may also indicate more space for embryo incubation, and be independent of the existence of correlation between female size and fecundity. For this purpose, we investigated whether the sternite width, and the height and width of pleura of second abdominal somite are correlated with fecundity.

\section{MATERIAL AND METHODS}

Embryo-carrying individuals were collected in December 2016 and February 2017 in a tidal mudflat in the estuary of the Paripe River, Ilha de Itamaracá, Pernambuco, Brazil $\left(07^{\circ} 48^{\prime} 38.0^{\prime \prime} \mathrm{S}, 34^{\circ} 51^{\prime} 22.1^{\prime \prime} \mathrm{W}\right)$. The specimens were captured by stepping on the mud surface where burrow openings of the alpheid $A$. estuariensis (where $S$. carvachoi is commonly found in association) were present. Due to the stepping, the shrimps leave the burrows and swim in the water film where they can be captured with small hand nets and examined. Individuals with embryos in the abdomen were placed into plastic flasks filled with water from the site, transported to the laboratory, anesthetized on ice, and fixed in formalin 5\%.

The individuals were photographed in a stereomicroscope with an image capture system. The software ImageJ 1.45 s (Rasband, 2006) was used to measure the following variables: carapace length $(\mathrm{CL})$ (distance from the tip of the rostrum to the posterior margin of the carapace); sternite width (SW) (distance between the lower limits of two pleurae of the second abdominal somite); height of the pleura of the second abdominal somite $\mathrm{PH}$ ) (distance between the lower and upper limits of the pleura); and width of the pleura of the second abdominal somite (PW) (distance between the posterior and anterior limits of the pleura) (Fig. 1). Except for $C L$, which was measured in all embryo-carrying individuals, the other variables were measured only in individuals carrying embryos at the initial stage of development.

The embryos were removed from the pleopods with the use of a brush, placed in a Petri dish, counted and separated in three stages of development, according to Wehrtmann's (1990) classification: initial stage (I) embryos with no evidence of eyes; yolk occupying $75-100 \%$ of embryo volume; intermediate stage (II) embryos with small and elongated eyes; yolk occupying about 50-75\% of embryo volume; final stage (III) embryos with well-developed eyes; yolk occupying $25-50 \%$ of embryo volume. In some individuals it was not possible to determine the embryo development stage as they had a whitish appearance and the eyes and the amount of yolk were not visible.

To calculate the embryo volume, the longest and shortest diameters of all embryos were measured (with the same procedure as for the other variables explained above). These values were used in the formula proposed by Bauer (1991): $\mathrm{V}=(\pi / 6) \times \mathrm{d} 1^{2} \times \mathrm{d} 2$, where $\mathrm{v}=$ volume $\left(\mathrm{mm}^{3}\right), \mathrm{d} 1=$ shortest diameter and $\mathrm{d} 2$ = longest diameter. The mean embryo volume in each stage of development was calculated. Mean fecundity was obtained through the total number of embryos at the initial stage only, in order to avoid possible bias due to embryo loss in stages II and III (Balasundaram \& Pandian, 1982). 
The relationship between fecundity vs. CL, fecundity vs. PH, fecundity vs. PW, and fecundity vs. SW were verified using linear regressions. The best adjusted model was the linear function $y=b x+a$, where the $y$ is the

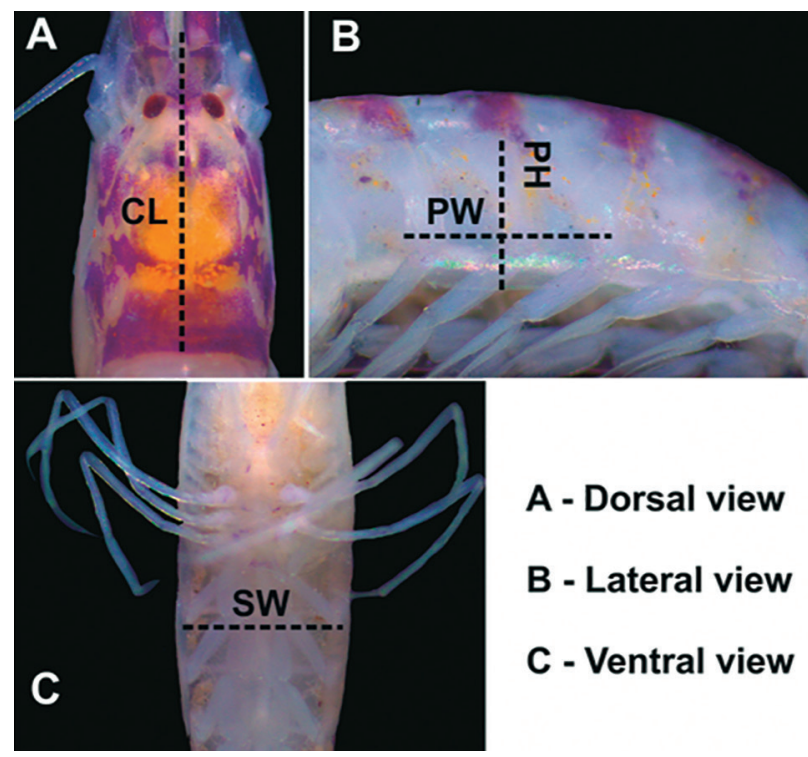

Figure 1. Measurements of morphological characters of Salmoneus carvachoi obtained from the Paripe River estuary, Pernambuco, northeastern Brazil, in December 2016 and February 2017. CL: Carapace Length; PW: Pleura Width; PH: Pleura Height and SW: Sternite Width.
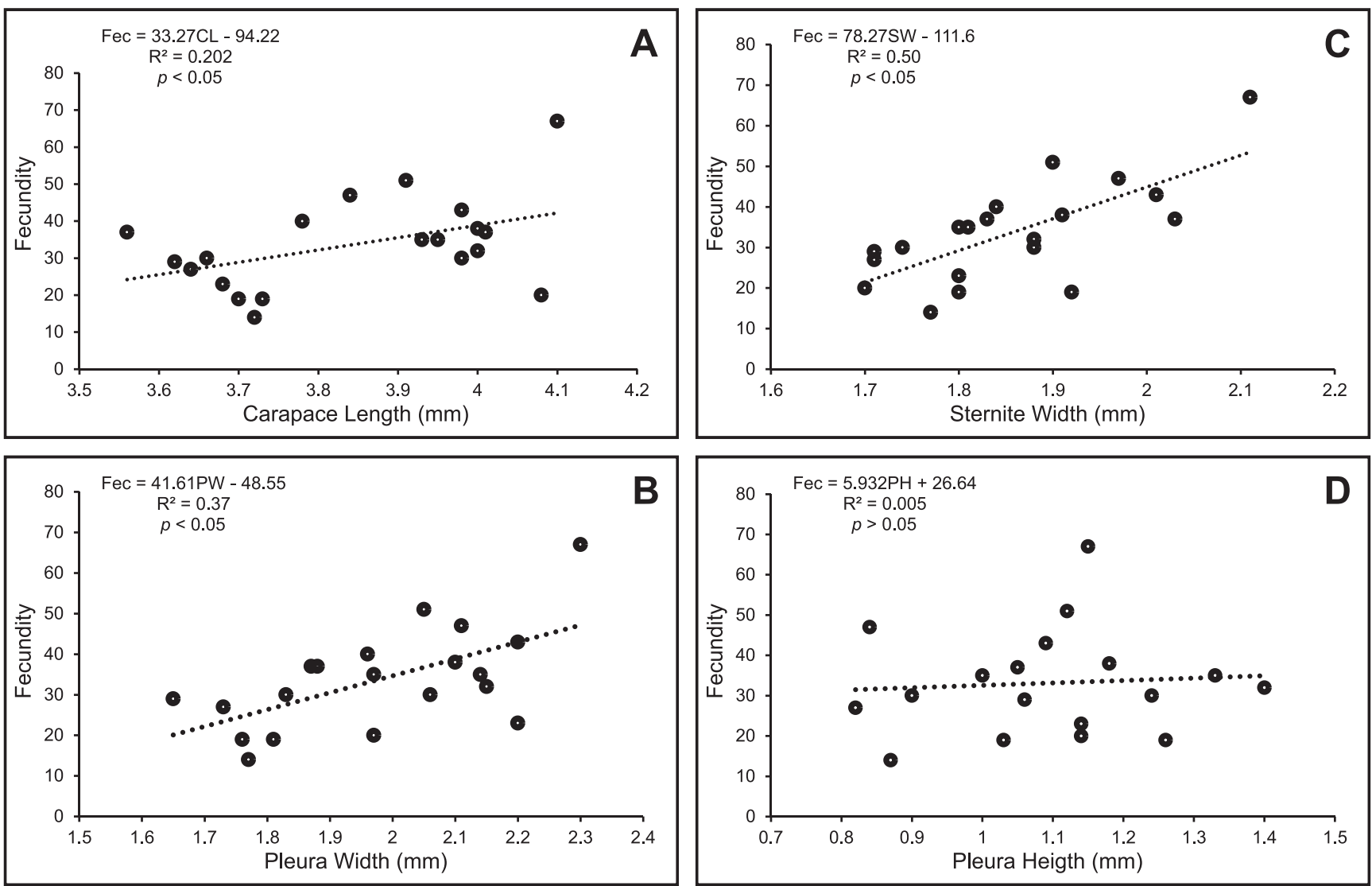

fecundity, the dependent variable, and $x$ is one of the biometric measures $(\mathrm{CL}, \mathrm{PH}, \mathrm{PW}$ or $\mathrm{SW})$, the independent variable. An Analysis of Covariance (ANCOVA) was used to verify if there are differences between these relationships. An ANCOVA with a posteriori Student's t-test was used to verify the variation in fecundity between development stages, i.e., to verify loss of embryos along the development. For the embryo volume, a one-way Analysis of Variance (ANOVA) with Student's t-test a posteriori was used to test differences between stages. The level of significance used in the tests was $a=0.05$.

\section{RESULTS}

We collected a total of 53 embryo-carrying individuals, including eight where the embryo masses could not be classified. Overall, CL ranged from 3.23 to $4.64 \mathrm{~mm}$ $(3.78 \pm 0.26 \mathrm{~mm})$. In individuals carrying embryos in stage I, SW ranged from 1.7 to $2.11 \mathrm{~mm}(1.85 \pm 0.11 \mathrm{~mm})$, PW ranged from 1.65 to $2.3 \mathrm{~mm}(1.95 \pm 0.17 \mathrm{~mm})$, and $\mathrm{PH}$ ranged from 0.78 to $1.6(1.09 \pm 0.21 \mathrm{~mm})$.

There was a weak positive correlation between fecundity and $C L(F=4.56$, d.f. $=1, p<0.05)$ (Fig. $2 A)$. Positive correlations were observed between fecundity and PW ( $F=17.86$, d.f. $=1, p<0.05)$, and fecundity and SW $(F=10.52$, d.f. $=1, p<0.05)$, indicating that the larger these dimensions, the larger the number of embryos

Figure 2. Correlations between fecundity and carapace length (A), width of the pleura of the second abdominal somite (B), sternite width measured at the level of the second abdominal somite (C), and pleura height of the second abdominal somite (D). Specimens of Salmoneus carvachoi were obtained from the Paripe River estuary, Pernambuco, northeastern Brazil, in December 2016 and February 2017. 


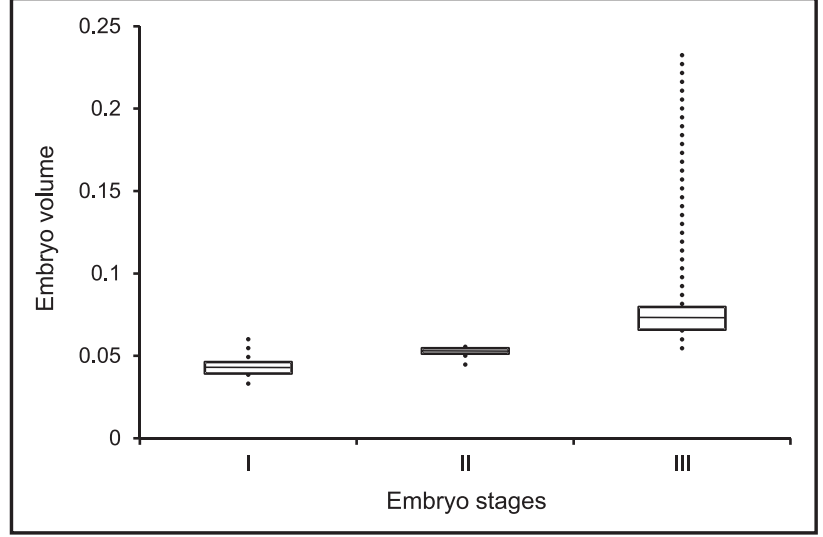

Figure 3. Comparison of mean embryo volume at the initial (I), intermediate (II), and final stage of development in Salmoneus carvachoi obtained from the Paripe River estuary, Pernambuco, northeastern Brazil, in December 2016 and February 2017.

carried (Fig. 2B, C). There was no correlation between fecundity and $\mathrm{PH}(\mathrm{F}=0.08$, d.f. $=1, \mathrm{p}>0.05)$ (Fig. 2D). The analysis of covariance demonstrated that there were no differences between the slopes describing the relationship between fecundity vs. CL, PW and SW (F=1.644, $p>0.05)$, indicating that these three structures are good predictors of fecundity.

The volume of stage I embryos varied from 0.03 to $0.06 \mathrm{~mm}^{3}\left(0.04 \pm 0.005 \mathrm{~mm}^{3}\right)$, from 0.04 to $0.05 \mathrm{~mm}^{3}$ $\left(0.05 \pm 0.003 \mathrm{~mm}^{3}\right)$ in stage II, and from 0.05 to $0.09 \mathrm{~mm}^{3}$ $(0.07 \pm 0.008)$ in stage III (Fig. 3$)$. There was a significant difference in embryo mean volume between stages I and II, and between stages I and III, but between stages II and III there was no significant difference $(F=73.36$, d.f. $=34.31$, $\mathrm{p}<0.005$ ) (Table 1), indicating that there was a significant increase in volume from stage I to II, but it remained the same from stage II to III. We observed a total increase of 93\% in embryo mean volume from stage I to III (Table 1).

We obtained 25 individuals with embryos in stages I, 5 in stage II and 15 in stage III. The mean fecundity (based on females carrying embryos in stage I) was $33.65 \pm 12.51$ embryos per individual, ranging from 14 to 67. There was a significant decrease $(F=52.35$, d.f. $=2$, $\mathrm{p}<0.05$ ) in mean fecundity between stages I and II (t test a posteriori, $\mathrm{p}<0.05$ ), and between I and III (t test a posteriori, $\mathrm{p}<0.05)$, due to embryo loss from the initial to the intermediate stage. The fecundity did not change between the intermediate and final stage (Table 1).

\section{DISCUSSION}

In S. carvachoi, a weak positive correlation was observed between fecundity and female size (CL). This result differs from what has been observed in most of studies on caridean shrimps (Balasundaram \& Pandian, 1982; Bauer, 1991; Corey \& Reid, 1991; Anger \& Moreira, 1998, Pavanelli et al., 2008, 2010; Costa-Souza et al., 2014; Rebolledo et al., 2014; Pescinelli et al., 2016). A positive correlation between fecundity and SW (sternite width), and between fecundity and PW (width of the pleura of the second abdominal somite) was observed. These positive correlations were expected, since the larger the female, the larger the size of such body parts, providing more space in the abdomen to harbor the embryo mass (Corey \& Reid, 1991; Lardies \& Wehrtmann, 1997; Anger \& Moreira, 1998). However, there was no positive correlation between fecundity and pleura height (height of the pleura of the second abdominal somite), a variable that could also indicate an increased abdominal space to carry more embryos (Fig. 2D).

The mean embryo volume in S. carvachoi was relatively small compared to other alpheids of the genus Alpheus, Betaeus and Synalpheus, with few exceptions (see Soledade et al., 2017). Only A. normanni Kingsley, 1878 , a species of similar size (mean CL of $4.5 \mathrm{~mm}$ and mean embryo volume of $0.03 \mathrm{~mm}^{3}$ ) (Bauer, 1991), has an embryo volume similar to $S$. carvachoi. The embryo size in crustaceans may be determined by genetic and environmental factors, which can influence in the type/ duration of the embryonic development of each species (Raven, 1961; Sastry, 1983; Bauer, 1991). Unlike most species of the three genera mentioned above, which have a larger $C L$ and embryo volume, the relatively small embryo size of S. carvachoi may be explained by its smaller body size. On the other hand, although some species of Synalpheus, such as S. brooksi Coutière, 1909, S. herricki Coutière, 1909, S. idios Ríos \& Duffy, 2007, S. pectiniger Coutière, 1907, and S. agelas Pequegnat \& Heard, 1979, are similar to S. carvachoi in $\mathrm{CL}$ (Table 2), their embryo volume are higher. Species of Alpheus and Betaeus, larger than S. carvachoi, also have higher embryo volume. This may be related to the developmental strategy adopted by these species of Synalpheus, where there is a higher investment in embryonic volume and a small number of eggs. This pattern is observed in species with direct or abbreviated development (Wehrtmann \& Albornoz, 2002), as for example, the eusocial species of Synalpheus, which have an abbreviated larval development (Duffy, 1996).

Considerable increases in embryo volume throughout development have been often observed in caridean shrimps (Corey \& Reid, 1991; Mossolin et al., 2006; Pavanelli et al., 2008, 2010). This is mainly due to water uptake, which facilitates the membrane rupture at the time of larvae hatching (Wear, 1974; Lardies \& Wehrtmann, 1996, 1997). Although the mean volume of embryos in stage III was relatively higher than in stage II, this difference was not statistically significant. The embryos increased $93 \%$ in volume, which may be considered a relatively high increase compared to the observed in some species of Alpheus, such as $A$. carlae Anker, 2012 [as A. armillatus (H. Milne Edwards, 1834)] (64.3\%; see Pavanelli et al., 2008), A. estuariensis (45.4\%; see Costa-Souza et al., 2014), A. brasileiro Anker, 2012 (35.4\%; see Pescinelli et al., 2016), and Synalpheus apioceros Coutière, 1909 (77.2\%, see Rebolledo et al., 2014). On the other hand, the increase in embryo size is relatively smaller compared to Betaeus emarginatus $\mathrm{H}$. Milne Edwards, 1837 (116.2\%; see Lardies \& Wehrtmann, 1997) and $B$. truncatus from the Guanaqueros, Chile (94.4\%; see Lardies \& Wehrtmann, 2001). 
Table 1. Mean fecundity, mean embryo volume $\left(\mathrm{mm}^{3}\right)$, and \% increase in embryo volume between three stages of embryo development, measured in ovigerous individuals of S. carvachoi obtained in December 2016 and February 2017 in the Paripe River estuary, Pernambuco, northeastern Brazil.

\begin{tabular}{cccc}
\hline Stages & N (number of individuals) & Mean fecundity \pm SD & Mean embryo volume $\left(\mathbf{m m}^{3}\right) \pm$ SD \\
\hline I & 25 & $33.65 \pm 12.51 \mathrm{a}$ & $0.043 \pm 0.005 \mathrm{a}$ \\
II & 5 & $3.2 \pm 2.58 \mathrm{~b}$ & $0.052 \pm 0.003 \mathrm{~b}$ \\
III & 15 & $2.53 \pm 1.92 \mathrm{~b}$ & $0.071 \pm 0.008 \mathrm{~b}$ \\
\hline
\end{tabular}

Values with at least one same small letter in each column did not differ between stages $(p=0.05)$.

Table 2. Mean carapace length, fecundity and embryo volume of six species of Synalpheus with carapace length (CL) similar to Salmoneus carvachoi. Min = Minimum and Max $=$ Maximum.

\begin{tabular}{|c|c|c|c|c|c|}
\hline Species & $\mathbf{N}$ & $\begin{array}{c}\text { Mean CL (mm) } \\
(\text { Min-Max) }\end{array}$ & $\begin{array}{c}\text { Fecundity Mean } \\
\text { (Min-Max) }\end{array}$ & $\begin{array}{c}\text { Mean embryo volume } \\
\left(\mathrm{mm}^{3}\right)(\text { Min-Max })\end{array}$ & Reference \\
\hline Synalpheus agelas & 5 & $\begin{array}{c}5.0 \\
(4.2-5.6)\end{array}$ & $\begin{array}{c}42.4 \\
(16-65)\end{array}$ & 0.23 & Corey \& Reid (1991) \\
\hline S. broosksi & 10 & $\begin{array}{c}3.9 \\
(3.4-4.5)\end{array}$ & $\begin{array}{c}5.8 \\
(3-11)\end{array}$ & 0.50 & \\
\hline S. herricki & 4 & $\begin{array}{c}4.5 \\
(3.5-5.12)\end{array}$ & $\begin{array}{c}45.8 \\
(11-81)\end{array}$ & 0.22 & \\
\hline S. pectiniger & 31 & $\begin{array}{c}4.2 \\
(3.5-4.6) \\
\end{array}$ & $\begin{array}{c}9.9 \\
(4-17) \\
\end{array}$ & 0.75 & \\
\hline S. chacei & 2 & 3.7 & 16 & 0.15 & Hernáez et al. (2010) \\
\hline S.idios & 4 & $\begin{array}{c}3.9 \pm 0.2 \\
(3.7-4.2) \\
\end{array}$ & $\begin{array}{l}12 \pm 4.3 \\
(9-18) \\
\end{array}$ & $\begin{array}{l}1.04 \pm 0.23 \\
(0.7-1.2) \\
\end{array}$ & \\
\hline Salmoneus carvachoi & 53 & $\begin{array}{c}3.78 \pm 0.26 \\
(3.23-4.64)\end{array}$ & $\begin{array}{c}33.65 \pm 12.51 \\
(14-67)\end{array}$ & $\begin{array}{c}0.043 \pm 0.005 \\
(0.03-0.06)\end{array}$ & Present study \\
\hline
\end{tabular}

The mean fecundity of S. carvachoi was higher than that of four species of Synalpheus of similar size: S. brooksi, S. pectiniger, S. chacei Duffy, 1998 and S. idios (Table 2). A similar fecundity was observed in two other species of Synalpheus: S. agelas and S. herricki (Table 2). The low fecundity of S. carvachoi, as compared to most species of Synalpheus, Alpheus, and Betaeus (Corey \& Reid, 1991; Rebolledo et al., 2014; Soledade et al., 2017), is probably related to its small body size, which offers less space in the body cavity to accommodate oocyte growth during ovarian maturation, and less space in the abdomen to carry a large embryo mass (Bauer, 1991; Corey \& Reid, 1991).

In caridean shrimps there is usually an inverse relationship between fecundity and egg volume (Corey \& Reid, 1991; Lardies \& Wehrtmann, 1997, 2001; Harikrishnan et al., 2010). A species may invest in a small number of embryos of a larger volume or in a higher number of embryos of smaller volume (Lardies \& Wehrtmann, 1997, 2001; Pavanelli et al., 2008, 2010). Salmoneus carvachoi apparently produces larger but less numerous embryos.

The embryo loss during incubation observed in most caridean shrimps occurs mainly due to the space limitation in the female's abdomen as the embryos increase in volume (Corey \& Reid, 1991; Wehrtmann \& Lardies, 1999). In addition, other factors may influence this process such as the presence of parasites, maternal cannibalism, mechanical stress, and substrate abrasion, among others (Balasundaram \& Pandian, 1982). The significant decrease in fecundity from the initial to the intermediate stage was accompanied by a significant increase in embryo volume. In the same way, there was no embryo loss and no increase in embryo volume between the intermediate and final stages. The significant increase in embryo volume during the embryogenesis might explain the em- bryo loss in S. carvachoi, as is commonly observed in other species of caridean shrimps (Balasundaram \& Pandian, 1982; Corey \& Reid, 1991; Anger \& Moreira, 1998).

\section{CONCLUSIONS}

The present study provides the first information on embryo production by the poorly known S. carvachoi, which is the first species of the genus to have its reproductive biology studied in more detail. Fecundity was weakly positively correlated with $\mathrm{CL}$, and SW and PW were better proxies of fecundity. Embryo volume undergoes a significant increase (93\%) from the initial to the final stage of development, which may explain the embryo loss seen during development. Future studies on the embryo production by other species of Salmoneus are necessary to compare these aspects of their reproductive biology.

\section{ACKNOWLEDGEMENTS}

We would like to thank the "Programa de PósGraduação em Zoologia" of UESC for support; MVO and ACC-S would like to thank the "Fundação de Amparo à Pesquisa do Estado da Bahia" (FAPESB) and "Coordenação de Aperfeiçoamento de Pessoal de Nível Superior" (CAPES - Finance Code 001) for granting a Master and Ph.D. scholarship, respectively; AOA is thankful to the "Conselho Nacional de Desenvolvimento Científico e Tecnólogico" (CNPq) for the Research Scholarship support (305939/2015-7). Finally, we thank Guidomar Soledade, Patricia Santos, and Renata Lima for their support during the field samplings. 


\section{REFERENCES}

Almeida, A.0;; Boehs, G.; Araújo-Silva, C.L. \& Bezerra, L.E.A. 2012. Shallowwater caridean shrimps from southern Bahia, Brazil, including the first record of Synalpheus ul (Ríos \& Duffy, 2007) (Alpheidae) in the southwestern Atlantic Ocean. Zootaxa, 3347: 1-35.

Anger, K. \& Moreira, G.S. 1998. Morphometric and reproductive traits of tropical caridean shrimps. Journal of Crustacean Biology, 18: 823-838.

Anker, A. 2007. New species and records of alpheid shrimps, genera Salmoneus Holthuis and Parabetaeus Coutière, from the tropical western Atlantic (Decapoda, Caridea). Zootaxa, 1653: 21-39.

Anker, A. 2010. The shrimp genus Salmoneus Holthuis, 1955 (Crustacea, Decapoda, Alpheidae) in the tropical western Atlantic, with description of five new species. Zootaxa, 2372: 177-205.

Anker, A. 2011a. Three new species of the alpheid shrimp genus Salmoneus Holthuis, 1955 (Crustacea, Decapoda) from the tropical western Pacific. Zootaxa, 2839: 67-84.

Anker, A. 2011b. Two new species of Salmoneus Holthuis, 1955 with a deep dorsal depression on the carapace (Crustacea, Decapoda, Alpheidae). Zootaxa, 3041: 39-50.

Anker, A. \& Lazarus, J.F. 2015. On two new species of the shrimp genus Salmoneus Holthuis, 1955 (Decapoda, Caridea, Alpheidae) from the tropical eastern Pacific. Zootaxa, 3957: 520-534.

Anker, A.; Firdaus, M. \& Pratama, I.S. 2014. Salmoneus yoyo nov. sp., a peculiar new infaunal shrimp from Lombok, Indonesia (Decapoda, Caridea, Alpheidae). Zootaxa, 3852: 489-495.

Atkinson, R.J.A.; Gramitto, M.E. \& Froglia, C. 2003. Aspects of the biology of the burrowing shrimp Alpheus glaber (Olivi) (Decapoda: Caridea: Alpheidae) from the Central Adriatic. Ophelia, 57: 27-42.

Balasundaram, C. \& Pandian, T. 1982. Egg loss during incubation in Macrobrachium nobilii (Henderson \& Mathai). Journal of Experimental Marine Biology and Ecology, 59: 289-299.

Bauer, R.T. 1991. Analysis of embryo production in a caridean shrimp guild from a tropical seagrass meadow. In: Wenner, A. \& Kuris, A. (Eds.). Crustacean egg production. Balkema, Rotterdam, p. 181-191.

Bauer, R.T. 2004. Remarkable Shrimps: Adaptations and Natural History of the Carideans. Norman, OK, University of Oklahoma Press.

Bazán, M.; Gámez, S. \& Reyes, W.E. 2009. Rendimiento reproductivo de hembras de Cryphiops caementarius (Crustacea: Palaemonidae) mantenidas con alimento natural. Revista Peruana de Biología, 12: 191-193.

Christoffersen, M.L. 1982. Geographic distribution of warm water alpheoid shrimp (Crustacea, Caridea) on the continental shelf of eastern South America between 23 and $35^{\circ}$ Lat. S. Boletim do Instituto Oceanográfico, 31: 93-112.

Corey, S. \& Reid, D.M. 1991. Comparative fecundity of decapods crustaceans, I. The fecundity of thirty-three species of nine families of caridean shrimps. Crustaceana, 60: 270-294.

Costa-Souza, A.C.; Rocha, S.S.; Bezerra, L.E.A. \& Almeida, A.0. 2014. Breeding and heterosexual pairing in the snapping shrimp Alpheus estuariensis (Caridea: Alpheidae) in a tropical bay in northeastern Brazil. Journal of Crustacean Biology, 34: 593-603.

De Grave, S. \& Fransen, C.H.J.M. 2011. Carideorum catalogus: the recent species of the dendrobrachiate, stenopodidean, procarididean and caridean shrimps (Crustacea: Decapoda). Zoologische Mededelingen, 85: 195-588.

Duffy, J.E. 1996. Eusociality in a coral-reef shrimp. Nature, 381:512-514.

Ďuriš, Z. \& Horká, I. 2016. Salmoneus chadwickae, a new alpheid shrimp (Crustacea: Decapoda: Alpheidae) from the Red Sea, with remarks on related or regional congeners. Marine Biodiversity, 46: 773-793.
Fernández-Muñoz, R. \& García-Raso, J.E. 1987. Study of a population of Alpheus dentipes Guerin, 1832 from calcareous bottoms in the southern Spain. Investigaciones Pesqueras, 51: 343-359.

Harikrishnan, M.; Unnikrishnan, U.; Maju, M.S.; Greeshma, A.R.R. \& Kurup, B.M. 2010. Size at sexual maturity, egg number and reproductive output of the snapping shrimp Alpheus euphrosyne euphrosyne De Man, 1987. Invertebrate Reproduction \& Development, 54: 195-202.

Hattori, G.Y. \& Pinheiro, M.A.A. 2003. Fertilidade do caranguejo de mangue Ucides cordatus (Linnaeus) (Crustacea, Brachyura, Ocypodidae), em Iguape (São Paulo, Brasil). Revista Brasileira de Zoologia, 20: 309-313.

Hernáez, P.; Martínez-Guerrero, B.; Anker, A. \& Wehrtmann, I.S. 2010. Fecundity and effects of bopyrid infestation on egg production in the Caribbean sponge-dwelling snapping shrimp Synalpheus yano (Decapoda: Alpheidae). Journal of the Marine Biological Association of the United Kingdom, 90: 691-698.

Komai, T. \& Anker, A. 2012. A distinctive new species of the alpheid genus Salmoneus Holthuis, 1955 (Crustacea: Decapoda: Caridea) from the northwestern Pacific. Zootaxa, 3344: 60-68.

Komai, T.; Yamada, Y. \& Yunokawa, K. 2015. A new cave-dwelling species of the alpheid shrimp genus Salmoneus Holthuis, 1955 (Crustacea: Decapoda: (aridea) from the Ryukyu Islands, southern Japan. Zootaxa, 4028: 413-420.

Lardies, M.A. \& Wehrtmann, I.S. 1996. Aspects of the reproductive biology of Petrolisthes laevigatus (Guérin, 1835) (Decapoda: Anomura: Porcellanidae). I. Reproductive output and chemical composition of eggs during embryonic development. Archive of Fishery and Marine Research, 43: 121-135.

Lardies, M.A. \& Wehrtmann, I.S. 1997. Egg production in Betaeus emarginatus (H. Milne Edwards, 1837) (Decapoda: Alpheidae): fecundity, reproductive output and chemical composition of eggs. Ophelia, 46: 165-174.

Lardies, M.A.\&Wehrtmann, I.S. 2001. Latitudinal variation in the reproductive biology of Betaeus truncatus (Decapoda: Alpheidae) along the Chilean coast. Ophelia, 55: 55-67.

Mossolin, E.C.; Shimizu, R.M. \& Bueno, S.L.S. 2006. Population structure of Alpheus armillatus (Decapoda, Alpheidae) in São Sebastião and Ilhabela, southeastern Brazil. Journal of Crustacean Biology, 26: 48-54.

Oliveira, M.V.; Costa-Souza, A.C.; Guimarães, F.J.; Almeida, A.0. \& Baeza, J.A. 2015. Observations on the life history of a rare shrimp, Salmoneus carvachoi (Crustacea: Caridea: Alpheidae), a possible simultaneous hermaphrodite. Marine Biodiversity Records, 8: e141.

Pavanelli, C.A.; Mossolin, E.C. \& Mantelatto, F.L. 2008. Reproductive strategy of the snapping shrimp Alpheus armillatus H. Milne-Edwards, 1837 in the South Atlantic: fecundity, egg features, and reproductive output. Invertebrate Reproduction and Development, 52: 123-130.

Pavanelli, C.A.; Mossolin, E.C. \& Mantelatto, F.L. 2010. Maternal investment in egg production: environmental and population-specific effects on offspring performance in the snapping shrimp Alpheus nuttingi (Schmitt, 1924) (Decapoda, Alpheidae). Animal Biology, 60: 237-247.

Pescinelli, R.A.; Davanso, T.M. \& Costa, R.C. 2016. Social monogamy and egg production in the snapping shrimp Alpheus brasileiro (Caridea: Alpheidae) from the south-eastern coast of Brazil. Journal of the Marine Biological Association of the United Kingdom, 97(7): 1519-1526, 2017. [Ahead of Print, 2016]

Ramos-Porto, M.; Viana, G.F.S. \& Lacerda, P.R. 1994. Ocorrência de Salmoneus ortmanni (Rankin, 1898) no Nordeste brasileiro. Revista Nordestina de Zoologia, 1: 44-60.

Rasband, W.S. 2006. ImageJ: image processing and analysis in Java. Bethesda, MD: National Institutes of Health, Research Services Branch Bethesda, MD.

Raven, C.P. 1961. Oogenesis: The Storage of Developmental Information. London, Pergamon Press. 
Rebolledo, A.P.; Wehrtmann, I.S.; Felder, D.L. \& Mantelatto, F.L. 2014. Embryo production in the sponge-dwelling snapping shrimp Synalpheus apioceros (Decapoda, Alpheidae) from Bocas del Toro, Panama. Zookeys, 457: 227-238.

Sastry, A.N. 1983. Ecological Aspects of Reproduction. In: Vernberg, F.J. \& Vernberg, W.B. (Eds.). The Biology of Crustacea. Environmental Adaptations. New York, Academic Press. v. 8, p. 179-270.

Soledade, G.0.; Santos, P.S.; Pescinelli, R.A.; Costa, R.C. \& Almeida, A.0. 2017. Embryo production of two sympatric snapping shrimps of the genus Alpheus (Caridea: Alpheidae) from northeastern Brazil: a comparative approach. Thalassas, 33: 151-158.

Vera-Caripe, J.; Lira, C.; Montoya, H. \& Hernández-Flores, X. 2015. Primer hallazgo de Salmoneus carvachoi Anker, 2007 (Crustacea: Decapoda: Alpheidae) en aguas de Venezuela. Saber, Universidad de Oriente, Venezuela, 27: 347-351.

Wear, R.G. 1974. Incubation in British decapod Crustacea, and the effects of temperature on the rate and success of embryonic development. Journal of the Marine Biological Association of the United Kingdom, 54: 745-762.
Wehrtmann, I.S. 1990. Distribution and reproduction of Ambidexter panamense and Palaemonetes schmitti in Pacific Costa Rica (Crustacea, Decapoda). Revista de Biología Tropical, 38: 327-329.

Wehrtmann, I.S. \& Albornoz, L. 2002. Evidence of different reproductive traits in the transisthmian sister species, Alpheus saxidomus and A. simus (Decapoda, Caridea, Alpheidae): description of the first postembryonic stage. Marine Biology, 140: 605-612.

Wehrtmann, I.S. \& Graeve, M. 1998. Lipid composition and utilization in developing eggs of two tropical marine caridean shrimp (Decapoda; Caridea: Alpheidae: Palaemonidae). Comparative Biochemistry and Physiology Part B, 121: 457-463.

Wehrtmann, I.S. \& Lardies, M.A. 1999. Egg production of Austropandalus grayi (Decapoda, Caridea, Pandalidae) from the Magellan region. Scientia Marina, 63: 325-331. 